\title{
HERITAGE DOCUMENTATION AND KNOWLEDGE TRANSFER: A REPORT ON THE CIPA TROPICAL SCHOOL IN CANDI SEWU (INDONESIA)
}

\author{
A. Murtiyoso ${ }^{1 *}$, D. Suwardhi ${ }^{2}$, P. Grussenmeyer ${ }^{1}$, W.A. Fadilah ${ }^{3}$, K.N. Fauzan ${ }^{2}$, S.W. Trisyanti ${ }^{2}$, Brahmantara $^{4}$, H. Macher ${ }^{1}$ \\ ${ }^{1}$ Université de Strasbourg, INSA Strasbourg, CNRS, ICube Laboratory UMR 7357, Photogrammetry and Geomatics Group, 67000 \\ Strasbourg, France - (arnadi.murtiyoso, pierre.grussenmeyer, helene.macher)@insa-strasbourg.fr \\ 23D Modelling and Information System, Remote Sensing and GIS Research Group, Bandung Institute of Technology, Bandung, \\ Indonesia - deni@gd.itb.ac.id, kamal.fauzan55@gmail.com,shafarina.wahyu@students.itb.ac.id \\ ${ }^{3}$ Erasmus Mundus Joint Masters Programme in Smart Cities and Communities, International Hellenic University, Thessaloniki, \\ Greece-wfadilah@ihu.edu.gr \\ ${ }^{4}$ Borobudur Conservation Office, Magelang, Indonesia - bramantarayk@gmail.com
}

KEY WORDS: heritage, workshop, documentation, training, southeast asia

\begin{abstract}
:
Documentation of heritage objects has advanced significantly with the invention and development of many 3D sensors and processing algorithms. These technical advancements are of the utmost interest for cultural heritage stakeholders; knowledge transfer between key players is therefore essential and is indeed the main philosophy behind the CIPA Heritage Documentation as an organisation. In this paper we present a report on the CIPA Tropical School in the Candi Sewu temple complex in Indonesia. Organisational aspects will be described, as well as some technical results of the workshop. As public interest in the tropical school was quite high, we argue that this type of limited participant training event involving international partners and cross-disciplinary experts is a very powerful tool in knowledge dissemination. Furthermore, we encourage the organisation of such events in other places around the world.
\end{abstract}

\section{INTRODUCTION}

In August 2019, a CIPA workshop was held within the vicinities of the $8^{\text {th }}$ century Candi Sewu temple complex in the province of Central Java, Indonesia. The workshop, dubbed a "tropical school", aimed to document the temple using state-ofthe-art 3D sensors while at the same time giving training to international participants on best practices. Modelled on the similarly successful CIPA summer schools (Cardinale et al., 2013; Fiorillo et al., 2013) in Europe, the tropical school's objective is to gather interested experts (architects, archaeologists, conservationist, surveyors, etc.) specifically from the Southeast Asian region. Being a region with a myriad of under-documented ancient sites, we deemed the initiative an important step from a knowledge transfer point of view.

While the importance of heritage documentation has been stressed many times (Grussenmeyer et al., 2012; Suwardhi et al., 2015), the proper techniques and best practices still eludes many main users and stakeholders. This may be due to the gap between technical science (e.g. surveying) and the humanities (e.g. history and archaeology), something that CIPA is well aware of and indeed its raison d'etre. The summer school formula has also shown to be an effective way not only for knowledge transfer, but also in creating crucial links and networks in the heritage documentation world (Achille et al., 2018; Garcia-Fernandez and Medeiros, 2019).

Furthermore, while 2D documentation is a common practice, 3D heritage documentation techniques are generally underutilised in the Southeast Asian region. This is despite the rich heritage of the region, comprising different types of objects and buildings. Several studies focused on the $3 \mathrm{D}$ recording of
Southeast Asian heritage (Manajitprasert et al., 2019; Murtiyoso et al., 2019) and some precedents in knowledge transfer events exist (Tse et al., 2019). However, in general literature remains scarce with the exception of high-profile sites which are usually listed as UNESCO World Heritage such as Angkor Wat (Evans et al., 2013) or Borobudur (Suwardhi et al., 2015).

The initiative for the tropical school came from both Indonesian and French researchers to launch a workshop similar in format to previous CIPA summer schools for the Southeast Asian region. The aim of the tropical school was then a double pronged-one: an educational objective and a documentation objective. Through consultation with Indonesian partners, the site of Candi Sewu (Figure 1) was selected as an ideal candidate due to its strategic location.

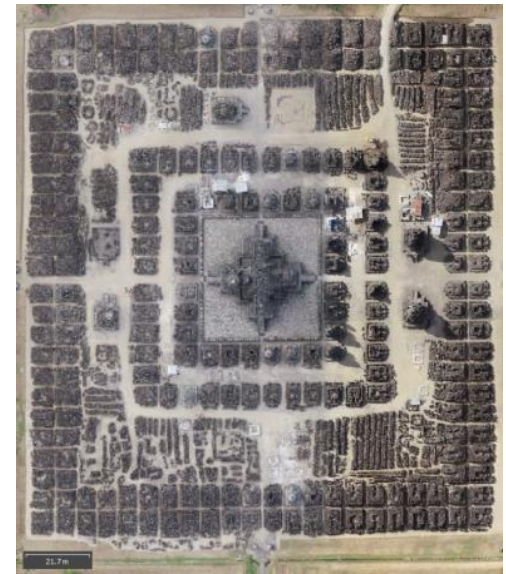

Figure 1. Orthophoto image of the Candi Sewu complex.

\footnotetext{
* Corresponding author
} 
The temple complex is located on the outskirts of a well-known tourist destination (Yogyakarta) with good transport infrastructure. However, while the site is located very near to the UNESCO World Heritage Prambanan Temple, it is much less known and therefore not many tourists visit the site. The temple complex itself is monumental, with over 259 individual structures covering a rectangular area of 4 hectares in a mandala pattern. Of this, 240 are small shrines ("perwara"), 8 are medium-sized flank temples ("apit") and one main central temple all laid out in a rectangular and symmetrical radiating pattern (a "mandala" pattern). This layout is a perfect site for a multi-group workshop. Although thoroughly documented in 2D in the form of photographs and drawings (Dumarçay and Lordereau, 2007), the temple has only been partially documented in 3D over the years. This presents a very interesting opportunity for the dual documentation and educational objectives of the project.

The main stakeholders in this project were mainly the public sector, represented by universities in both France and Indonesia and the Cultural Heritage Conservation Bureau of the province of Central Java (Indonesia). In addition, several private companies contributed in the form of sponsorships and lending of $3 \mathrm{D}$ documentation and surveying devices. This project was also of great interest as it enables an international exposure to this monumental site.

\section{ORGANISATIONAL ASPECTS}

\subsection{Preparations}

The tropical school was intended to be modelled from the annual CIPA summer schools, taking best practices from these precedents. The objective of the workshop was to introduce to archaeologists and cultural heritage activists about image based (close range and drone photogrammetry) and range based technology (laser scanning) in 3D modelling and their applications and advantages. The participants were understandably not expected to receive a thorough expertise from this workshop; the aim was therefore to create an awareness and general knowledge of the existence of these technologies, as a state-of-the-art technique and procedure in 3D digital documentation. The results of any such 3D acquisition may serve thereafter as a model for a spatial database to help the excavation, conservation, reconstruction or revitalisation of the heritage object in the future.

The event was co-organised by the Bandung Institute of Technology (Indonesia) and INSA Strasbourg (France), within the framework of the Franco-Indonesian PHC-NUSANTARA cooperation scheme. Furthermore, the Cultural Heritage Conservation Bureau of Central Java played a key role in determining the site of the tropical school and providing logistical support. Tutors for the workshop consisted of international experts from Bandung Institute of Technology, INSA Strasbourg, and the Borobudur Conservation Office. The tropical school was also supported by CIPA Heritage Documentation.

Due to the event being inside the framework of a FrancoIndonesian cooperation project, financing was partly supplied by the French and Indonesian governments as administered by CampusFrance. Additional sponsorship was also secured from private companies.

The targeted audience was scholars, MSc and PhD students, researchers and specialists, archaeologists, architects, restorers, conservationists, geomatic engineers, in the surveying and heritage fields. Participants were limited to 25 persons in order to create a more close-knit and therefore a more conducive environment for discussions. While the workshop was open for any international participants, the specific target from an organisational point of view was Southeast Asian participants. Registration was done using a selection based on potential participant CVs and motivation letters.

\subsection{Workshop Scheduling}

The tropical school was held over a period of six days, during which time participants were given both theoretical and practical lessons. Practical lessons concentrated on a hands-on approach to the use of various surveying and $3 \mathrm{D}$ tools as well as their post-processing. The main topics of the lessons are organised as follows: (1) terrestrial laser scanning, (2) handheld laser scanning, (3) close range photogrammetry, (4) terrestrial and drone photogrammetry, and (5) surveying. For each lesson module, two tutors were assigned. In addition, several other demonstrations of other technologies were schedules: aerial mapping using drone/UAV photography and lidar, and mobile SLAM-based 3D scan.

While the theoretical part was given in a lecture hall, participants were then divided into 5 groups for the practical part. Using a four-hour/half day time slots, each group rotates through each of the five practical modules (see illustration in Figure 2). Furthermore, to each group one shrine among the still intact structures of Candi Sewu was assigned. In this way, each group performed surveying and recorded their designated shrine using the four 3D techniques taught in the modules. Following two and half days ( 5 half day sessions), participants were given the opportunity to process the data they had acquired, mimicking post-acquisition office processing in documentation projects. During the final day, each group was then given an opportunity to present their results in front of the other participants and tutors.

\subsection{Expected Outcomes}

Two different outcomes were expected from this tropical school. First of all, the participants were expected to be able to understand the basics of $3 \mathrm{D}$ recording using the techniques described during the theoretical and practical lessons.

1. Terrestrial laser scanning: Aside from basic technical and operational knowledge, participants were expected to understand the principle of both point cloud registration and georeferencing.

2. Hand-held laser scanning: The knowledge of different types of laser scanner/lidar sensors were emphasised, as well as their different applications according to the case in hand.

3. Close range photogrammetry: The $3 \mathrm{D}$ reconstruction of small to medium objects, artefacts, as well as carvings and bas-relief using a standard DSLR camera was emphasised for this module.

4. Terrestrial and drone photogrammetry: This module focused more on larger objects such as buildings and how both terrestrial and drone photogrammetry may complement each other.

5. Surveying: The basics of surveying and mapping as often employed in archaeological settings were explained, including the use of GNSS and basic total station measurements and computation of coordinates. 


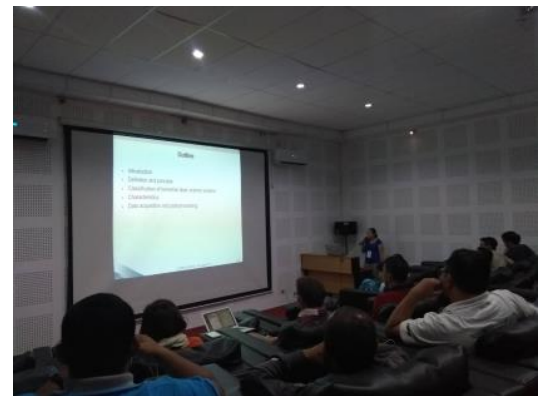

(a)

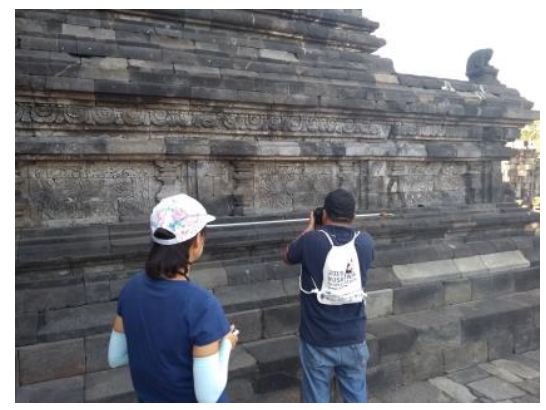

(d)

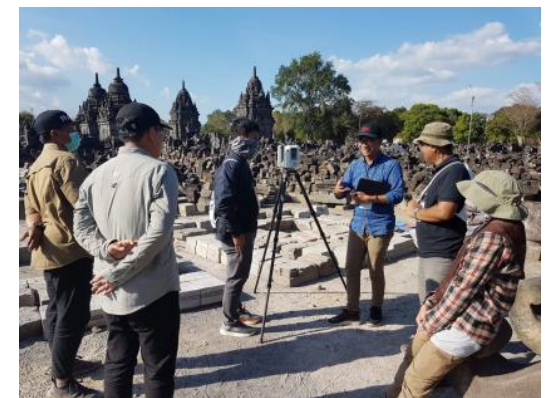

(b)

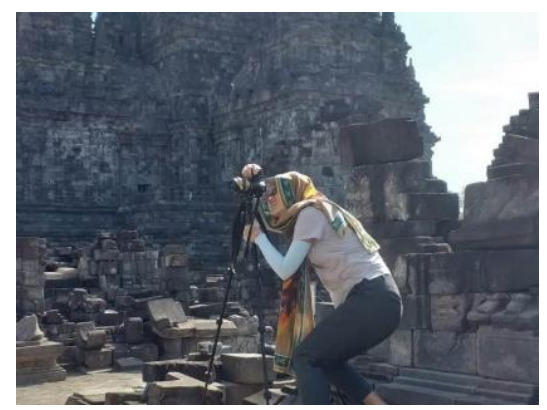

(e)

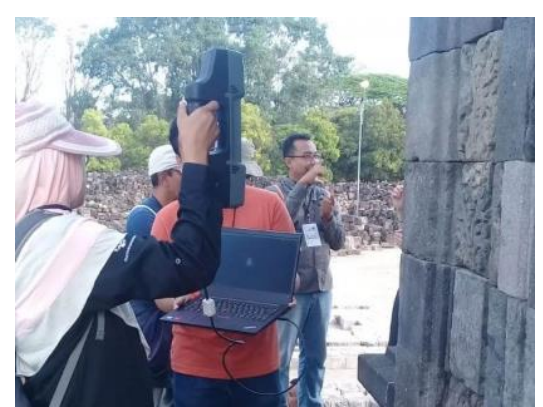

(c)

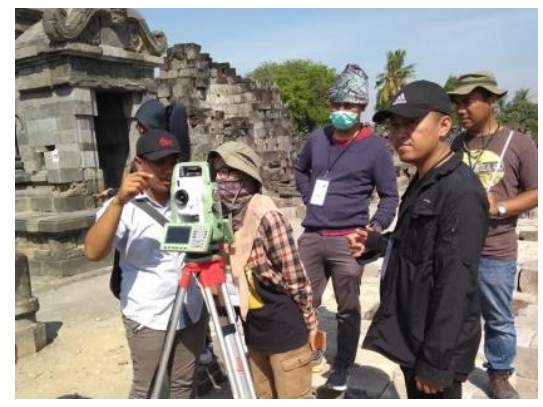

(f)

Figure 2. Documentation photos of the theoretical module (a) and the four practical modules: (b) terrestrial laser scanning, (c) handheld laser scanning, (d) close range photogrammetry, (e) terrestrial photogrammetry, and (f) surveying.

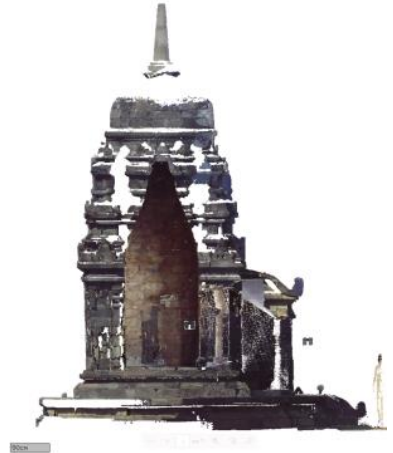

(a)

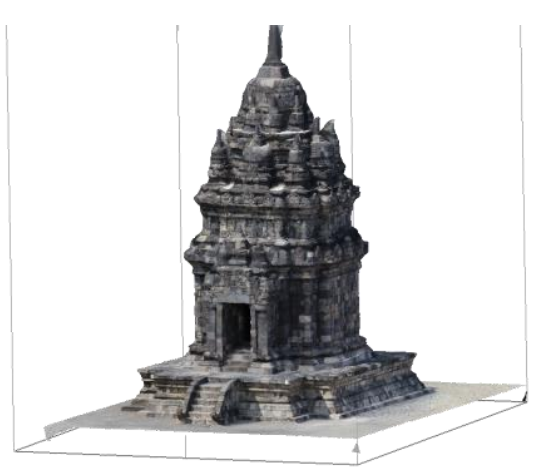

(b)

Figure 3. A sample of results from the tropical school as created by the participants: (a) laser scan of a shrine interior and (b) photogrammetic point cloud of the same shrine's exterior. Note that to each group one shrine was attributed.

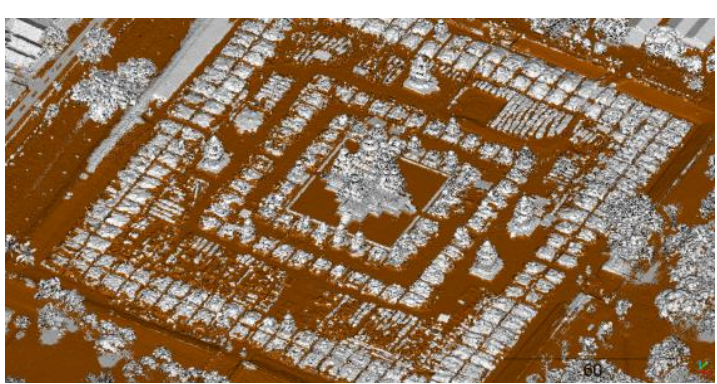

(a)

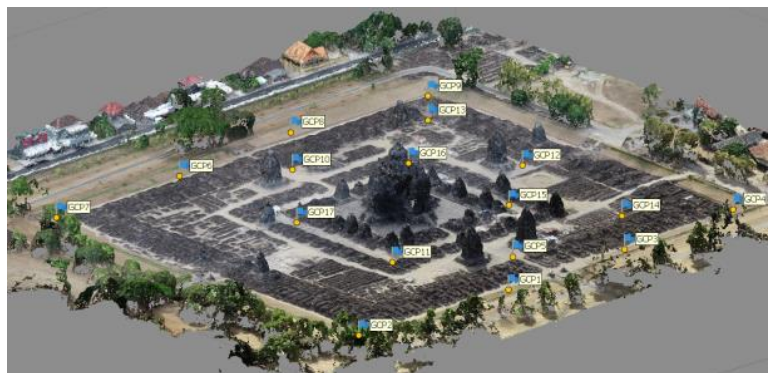

(b)

Figure 4. Some results of the documentation project and technical demonstrations: (a) lidar point cloud classified into ground and non-ground classes, (b) georeferenced drone photogrammetric point cloud.

The second outcome of the project was of a more technical nature. In addition to giving training to the participants, 3D documentation of the temple complex as a heritage site was also planned. Since this objective requires a stricter level of quality, this was mainly done using aerial drone photography and lidar. These acquisitions were not performed by the participants, but rather constituted a technical demonstration from which researchers were then able to derive geomatic products. Some additional data with a higher level of detail were also taken by tutors during the technical session, including close range images and TLS point clouds. 


\section{TECHNICAL ASPECTS}

\subsection{Documentation by participants}

Some of the results from the participants can be seen in Figure 3. As can be expected from training sessions with people of various scientific backgrounds (technical and non-technical), the quality of these results vary greatly. Indeed, no geometrical quality constraint was imposed on the participants as this is not the main aim of the training. The training was intended to explain the concepts and applications of 3D technique, while encouraging participants to look further beyond the tropical school if interested in more technical aspects of 3D recording.

Observations showed that technical use of terrestrial laser scanning seems to be the easiest for the participants to master. However, the concept of registration and georeferencing was nevertheless an important emphasis during the data processing phase. Photogrammetry was also easy enough to apply using modern software (Agisoft Metashape was used during the workshop); however participants particularly appreciated the discussions on best practices with tutors both on the acquisition and processing stages. Close range photogrammetry was particularly of interest due to its low cost nature and flexibility. Surveying was the most difficult part to explain to some participants since it involves more complex mathematical notions in practice. However, for most participants the most important aspect of surveying is to understand how coordinates can be measured to support both photogrammetry and laser scanning, as well as its importance in guaranteeing good results.

\subsection{Technical demonstrations}

In addition to theoretical and technical lessons, several demonstrations of other state-of-the-art techniques were also scheduled. This includes a demonstration on UAV lidar, aerial photogrammetry, and mobile mapping acquisitions. The participants do not directly perform the data processing on this type of acquisition, but the final results and main processing steps were shown. Furthermore, the processed lidar and aerial photogrammetric data (point cloud and orthophotos) were shared with the Cultural Heritage Conservation Bureau for use as digital documentation of the Candi Sewu temple complex. Some of the results of these technical demonstrations can be seen in Figure 4.

To support both aerial photogrammetry and UAV lidar missions, a thorough ground survey was also performed by researchers in parallel to the tropical school. These high precision ground control points cover the temple complex with a high density, thus ensuring high quality mapping of the area and even the possibility to use the data as benchmarks.

\section{CONCLUSIONS AND PERSPECTIVES}

From the point of view of knowledge transfer, the workshop was successful in gathering participants from various backgrounds. The overall statistics of participants' background can be seen in Figure 5. As can be seen from this figure, the tropical school attracted experts from various domains of which geomatics and architecture are dominant. It is worth noting that all five architects work in the cultural heritage or architectural history domain, while of the ten geomaticians a majority attended the course either because they have projects related to heritage or simply out of interest. Two conservators who also attended the tropical school also have backgrounds in architectural history.
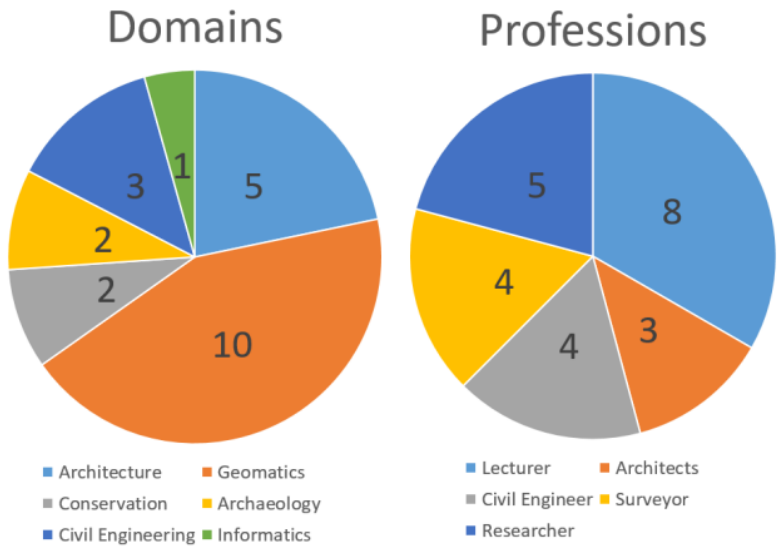

Figure 5. Statistics on participants' background.

Regarding the participants' professions, researchers and university lecturers dominate the statistics. This may be an indication that in this region $3 \mathrm{D}$ heritage documentation still remains within academia and has not yet penetrated as an industry. Most of the professionals attending the workshop are either surveyors or civil engineers, again either working on a heritage-related project or simply curious to state-of-the-art 3D techniques and applications.

Despite vigorous advertising, an overwhelming majority of participants are Indonesians, with one participant from Thailand and one from France. Although this is a somewhat expected outcome, we sincerely believe that more emphasis on international and regional outreach should be added if and when an iteration of the tropical school is held again in the future. We also recognise that logistical problems seem to discourage other participants from the Southeast Asian region from attending, a situation which is clearly in contrast to the European-based CIPA summer schools.

Furthermore, at the same time the project enabled a thorough 3D recording of the whole temple complex of Candi Sewu, albeit in various levels of details. The temple complex was scanned using both aerial photogrammetry and lidar, yielding very interesting results for local stakeholders. For several of the minor structures, a more detailed recording was also performed by the participants using terrestrial techniques. A network of ground control points was established in the temple complex, thus enabling future missions in the interest of monitoring and change detection.

In conclusion, this model of knowledge transfer is both very effective and generates high interest for the public. Similar models may be implemented in other parts of the world. We argue that such events should be replicated in parts of the world where 3D heritage documentation remain underutilised, as it is an excellent medium to disseminate technical knowledge to various heritage conservation stakeholders.

\section{ACKNOWLEDGEMENTS}

The authors wish to thank the sponsors for this tropical school: PT. Wisesa Berkah Bumi and Stonex, PT. Asaba, PT Leica Geosystems Indonesia, and PT. Inovasi Mandiri Pratama. We are also very grateful to the invaluable support given by the following institutions: CampusFrance (PHC Nusantara, FrenchIndonesian Science and Technology Cooperation Program), Borobudur Conservation Office, Ministry of Education and Culture of the Republic of Indonesia, Agisoft LLC and PT. Exsol Innovindo. 


\section{REFERENCES}

Achille, C., Fassi, F., Mandelli, A., Fiorillo, F., 2018. Surveying cultural heritage: summer school for conservation activities. Applied Geomatics 10, 579-592.

Cardinale, T., Valva, R., Lucarelli, M., 2013. Advanced Representation Technologies Applied To the Temple of Neptune, the Sphinx and the Metope in the Archaeological Park of Paestum. ISPRS - International Archives of the Photogrammetry, Remote Sensing and Spatial Information Sciences XL-5/W1, 35-41.

Dumarçay, J., Lordereau, P., 2007. Candi Sewu and Buddhist architecture of Central Java, Seri terjemahan arkeologi. Kepustakaan Populer Gramedia.

Evans, D.H., Fletcher, R.J., Pottier, C., Chevance, J.B., Soutif, D., Tan, B.S., Im, S., Ea, D., Tin, T., Kim, S., Cromarty, C., De Greef, S., Hanus, K., Bâty, P., Kuszinger, R., Shimoda, I., Boornazian, G., 2013. Uncovering archaeological landscapes at Angkor using lidar. Proceedings of the National Academy of Sciences of the United States of America 110, 12595-12600.

Fiorillo, F., Jiménez Fernández-Palacios, B., Remondino, F., Barba, S., 2013. 3d Surveying and modelling of the Archaeological Area of Paestum, Italy. Virtual Archaeology Review 4, 55-60.

Garcia-Fernandez, J., Medeiros, L., 2019. Integrating digital documentation and community engagement: "Unveiling the hidden hamina" international summer school. ISPRS Annals of the Photogrammetry, Remote Sensing and Spatial Information Sciences 4, 61-68.

Grussenmeyer, P., Burens, A., Moisan, E., Guillemin, S., Carozza, L., Bourrillon, R., Petrognani, S., 2012. 3D multiscale scanning of the archaeological cave les Fraux in Dordogne (France). Lecture Notes in Computer Science (including subseries Lecture Notes in Artificial Intelligence and Lecture Notes in Bioinformatics) 7616 LNCS, 388-395.

Manajitprasert, S., Tripathi, N.K., Arunplod, S., 2019. Threedimensional (3D) modeling of cultural heritage site using UAV imagery: A case study of the pagodas in Wat Maha That, Thailand. Applied Sciences (Switzerland) 9, 1-14.

Murtiyoso, A., Grussenmeyer, P., Suwardhi, D., Fadilah, W.A., Permana, H.A., Wicaksono, D., 2019. Multi-Sensor 3D Recording Pipeline for the Documentation of Javanese Temples, in: International Archives of the Photogrammetry, Remote Sensing and Spatial Information Sciences. pp. 829834.

Suwardhi, D., Menna, F., Remondino, F., Hanke, K., Akmalia, R., 2015. Digital 3D Borobudur - Integration of 3D Surveying and Modeling Techniques, in: The International Archives of the Photogrammetry, Remote Sensing and Spatial Information Sciences. pp. 417-423.

Tse, D., Paladini, A., Dhanda, A., Weigert, A., Reina Ortiz, M., Santana Quintero, M., Min, A., Gyi, M., Su, S., 2019. Conserving built heritage for posterity: a conservation approach in Bagan, in: International Archives of the Photogrammetry, Remote Sensing and Spatial Information Sciences - ISPRS Archives. pp. 1179-1185. 